\title{
TAKE A STAND
}

Dear Reader,

In my editorial in the middle of last year, I appealed to people to have more courage in expressing opinions. This applied, I wrote, not only to guest commentaries and interviews but also to technical articles. My appeal did not fall on deaf ears. As a result, it has given an even sharper edge to the character of ATZelektronik as an important platform for the exchange of ideas.

In this issue too, authors are prepared to take a stand. Professor Dr. Manfred Broy and Dr. Klaus Webers do not pull their punches in attacking inadequate requirements management in software development. Broy is holder of the Chair of Software \& Systems Engineering, while Webers is project manager for attribute-oriented design at BMW. Their position paper includes a veritable volley of criticism. But it is balanced by constructive solutions. Based on an analysis, some absolutely essential but fatally inadequately managedweak points of RE are demonstrated.

The authors of ATZelektronik will find support in our new section "Special Report”, which will provide space for discussion in every second issue. The title on page 14 is "Home-made cost trap". The article criticises the ongoing lack of standards in the electric drive train. No less than five experts from the supply sector give such a strong warning that more scepticism than confidence remains.

Unlike the Autosar software standard. Nevertheless, there have been demands for a paradigm shift here too. On page 42 , you can read the exclusive report about the technical and strategic reorientation of the consortium. Autosar has defined its goals for the post phase III organisation beginning in 2013.
Perhaps you can now recognise two character features of ATZelektronik more clearly: The technical articles and other reports are not simply strung together. Instead, they cross-reference each other wherever appropriate. What is more, we accompany developments over a period of years and stay on the ball until they have matured into innovations.

For this process of maturity, both you and we require a broad basis for a dialogue - and this basis grows with a broader readership. Please persuade others to read ATZelektronik. Not only is it worthwhile, it will also be rewarded: http://www.my-specializedknowledge.com/automotive/ atzelektronik-worldwide/.

Best regards,

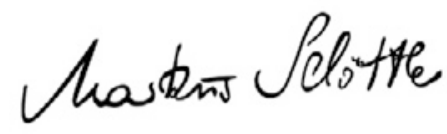

MARKUS SCHÖTTLE,

Vice-Editor in Chief

Wiesbaden, 9 January 2013

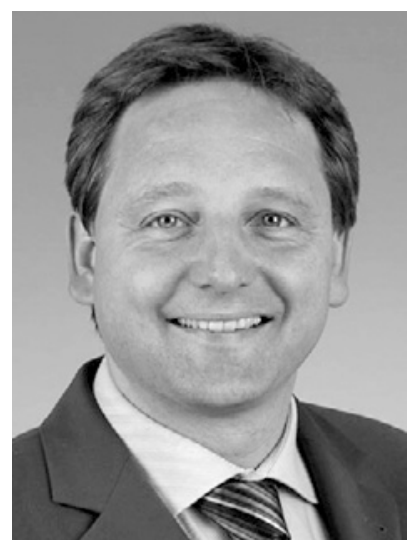

